\title{
Kernos
}

Revue internationale et pluridisciplinaire de religion grecque antique

8| 1995

Varia

\section{P. Hadot, Plotin. Traité 9 (VI, 9). Introduction, traduction, commentaire et notes}

André Motte

\section{(2) OpenEdition}

\section{Journals}

Édition électronique

URL : http://journals.openedition.org/kernos/616

DOI : 10.4000/kernos.616

ISSN : 2034-7871

Éditeur

Centre international d'étude de la religion grecque antique

Édition imprimée

Date de publication : 1 janvier 1995

Pagination : 307-308

ISSN : 0776-3824

\section{Référence électronique}

André Motte, «P. Hadot, Plotin. Traité $9(\mathrm{VI}, 9)$. Introduction, traduction, commentaire et notes », Kernos [En ligne], 8 | 1995, mis en ligne le 12 avril 2011, consulté le 24 septembre 2020. URL : http:// journals.openedition.org/kernos/616 ; DOI : https://doi.org/10.4000/kernos.616 
provient soit de la dispersion d'un centre commun, soit d'un développement spontané.

Le deuxième chapitre parle du XXe siècle et des nouvelles approches dans l'étude du mythe, profondément redevables des interprétations du siècle précédent : depuis J.E. Harrison, C.G. Jung, E. Durkheim, B. Malinowski, V. Propp, jusqu'à G. Dumézil, C. Lévi-Strauss, J.-P. Vernant, A. Brelich, W. Burkert, R. Barthes et C. Calame, entre autres.

Après cette vaste excursion au pays des interprétations modernes et contemporaines, le troisième chapitre nous replonge dans la matière même du mythe grec, et plus particulièrement dans ses relations avec l'épopée, assorties de la difficile question des « origines » et donc de la matière « pré-épique ». Viennent ensuite, avec le quatrième chapitre, les récits de l'origine du monde et des dieux, la Théogonie d'Hésiode et son arrière-plan oriental, la poésie cosmogonique postérieure et la réflexion philosophique sur les données du monde physique. Le cinquième chapitre parle des mythes " cultuels ", autour des sanctuaires et des fêtes, et repose le problème des relations entre le mythe et le rite autour des récits étiologiques. Les trois derniers chapitres abordent respectivement le mythe conçu comme «histoire» par les Grecs, son utilisation dans le chant choral et la tragédie, et la réflexion critique des Anciens sur leurs propres mythes.

Chaque donnée, ancienne ou moderne, est envisagée avec sympathie, dans un contexte qui lui donne un sens, notamment pour l'actualité de la recherche qui est pour beaucoup l'héritière d'un passé rappelé dans ses aspects les plus divers. À lire et à méditer pour combattre tout «terrorisme » intellectuel, toute vision exclusive. Comme l'écrit Ken Dowden dans une autre introduction à la mythologie grecque, we live in syncretistic times!

Vinciane PIRENNE-DELFORGE (Université de Liège)

Pierre HaDot, Plotin. Traité 9 (VI, 9). Introduction, traduction, commentaire et notes, Paris, Ed. du Cerf, 1994, 1 vol. 12,5 x 19,5 cm, 252 p. (Coll. Les écrits de Plotin publiés dans l'ordre chronologique sous la direction de Pierre Hadot ). ISBN : 2-204-05013-X. Prix : 150 FF.

C'est le 3 e volume paru de cette précieuse collection dont l'A. assure la réalisation avec une persévérante assiduité (pour les Traités $38(V I, 7)$ et 50 (III, 5) déjà publiés, cf. Kernos, 1 [1988], p. 253, et 5 [1992], p. 349); il est dédié à la mémoire de H.-R. SCHWYZER. Intitulé Du Bien ou de l'Un, un titre sans doute donné par Porphyre, le traité 9 est le dernier dans l'édition que le disciple a donnée des Ennéades, mais il compte en fait parmi les premiers que Plotin ait écrits. Il est consacré au Principe suprême et représente donc le sommet de sa théologie à dominante négative : aucun nom, pas même l'Un, ne convient pour dire cette Réalité suprême qui transcende l'Intellect. De l'Un, il n'est nulle connaissance, nulle science; on ne peut le saisir que dans une 
expérience où l'on s'assimile à lui et où on est soi-même 'un'. C'est dire que le discours théologique n'est jamais qu'une préparation intellectuelle préalable à cette union; il ne fait qu'indiquer la direction dans laquelle il faut aller, il n'est qu'une description des états dans lesquels se trouve l'âme par rapport à l'Un, une conception nouvelle, observe l'A., dans la tradition théologique grecque. C'est par la vie philosophique, - l'expérience de la vertu, de la purification, de l'unification, comme le précisera le traité 38 (VI, 7), - qu'on parvient à l'expérience mystique dont le présent traité offre la première description détaillée. Les derniers mots sont une invitation à imiter la vie des dieux et des hommes divins et bienheureux : «vivre sans prendre de plaisir dans les réalités d'ici-bas, fuir seul vers le Seul ».

D'autres références aux mythes et aux réalités religieuses de la Grèce parsèment le traité. À signaler notamment la figure de Minos, « le familier de Zeus " comme dit déjà Homère, pour symboliser l'union avec l'Un, une version originale du mythe de Psyché et d'Éros, en rapport avec les deux Aphrodite, pour signifier les tribulations de l'âme, l'image de la cboreia entheos tournant autour du divin choryphée, pour symboliser la contemplation psychique, et celle, très appuyée, de la vision du dieu à l'intérieur du sanctuaire, «Celui qui a vu sait ce que je dis » $(9,47)$ : la référence à une formule tradionnellement employée à propos des mystères éleusiniens est manifeste, et Plotin de proposer plus loin une intéressante exégèse du secret en honneur dans les «mystères d'ici-bas »: comment pourrait-on annoncer comme 'autre' cet objet de vision, alors qu'au moment où on l'a vu, on ne l'a pas vu 'autre', mais 'un' avec soi-même ? À qui n'a pas eu la chance de voir le divin, il est donc interdit de le divulguer parce que ce n'est pas possible.

Le lecteur identifiera aisément ces passages grâce aux divers index qui accompagnent l'ouvrage et auxquels est jointe une bibliographie des auteurs anciens et modernes. La fidélité et l'élégance de la traduction jointes à la clarté et à la pertinence des propos introductifs et des commentaires font que le but poursuivi par cette collection, - il est rappelé dans l'Avant-propos (p. 11), - est pleinement atteint : « rendre, dans la mesure du possible, les écrits de ce philosophe accessibles au lecteur moderne ". Mais sous la conduite d'un tel mystagogue, combien les initiés eux-mêmes trouvent encore matière à s'instruire! On souhaiterait seulement que l'A. s'explique sur l'ordre dans lequel il a choisi de publier successivement les traités, et qui n'est ni l'ordre systématique de l'édition porphyrienne, ni l'ordre chronologique que la collection entend lui substituer. Cette discordance ne risque-t-elle pas à la longue de compromettre la présentation harmonieuse de l'ensemble? 